\title{
Association between FAMACHA scores and fecal egg counts in Katahdin lambs $1,2,3$
}

\author{
D. R. Notter, ${ }^{* 4}$ J. M. Burke, $\uparrow$ J. E. Miller, $\$$ and J. L. M. Morgan§ \\ *Department of Animal and Poultry Sciences, Virginia Tech, Blacksburg 24061; †ARS, USDA, Dale Bumpers \\ Small Farms Research Center, Booneville, AR 72927; †Department of Pathobiological Sciences, School of Veterinary \\ Medicine, Louisiana State University, Baton Rouge 70803; §Katahdin Hair Sheep International, Fayetteville, AR 72702
}

\begin{abstract}
The FAMACHA system was introduced to the U.S. just over $10 \mathrm{yr}$ ago to allow selective deworming of lambs with anemia associated with Haemonchus contortus and retard the development of anthelmintic resistance. The FAMACHA system was initially developed as a predictor of packed cell volume (PCV), but correlations between FAMACHA and fecal egg counts (FEC) have also been reported. It is important to understand factors that influence FAMACHA scores among farms to improve management of gastrointestinal nematodes. The objectives of this study were therefore to quantify associations between FAMACHA scores, FEC, BW, and age in Katahdin lambs at 2 different measurement times in 8 flocks in the eastern U.S., and to assess consistency of relationships between FAMACHA and FEC among flocks. Data came from 1,644 Katahdin lambs from 7 flocks sampled at approximately $90 \mathrm{~d}$ of age, and 1,295 lambs from 6 flocks sampled at approximately $120 \mathrm{~d}$ of age over a $5 \mathrm{yr}$ period. Residual correlations among log-transformed FEC (LFEC), FAMACHA
\end{abstract}

scores, BW, and lamb ages at each measurement time were determined. Repeatability of each variable was also determined as residual correlations among repeated measures. At both 90 and $120 \mathrm{~d}$ of age, correlations of FAMACHA scores with LFEC and BW were significant $(P<0.001)$, but numerically modest $(0.25$ and -0.16 , respectively at $90 \mathrm{~d}$; 0.31 and -0.16 , respectively at $120 \mathrm{~d}$ ), demonstrating that higher FAMACHA scores were associated with higher FEC and more likely to be observed in lighter lambs. A small negative correlation was observed between FAMACHA score and lamb age $(r=-0.05, P=0.05,90 \mathrm{~d} ; r=-0.11, P<0.001,120$ d) indicating that younger lambs were more likely to have elevated FAMACHA scores. Thus, younger and lighter lambs will likely be more susceptible to parasitism and may need to be managed more diligently than older or heavier lambs. In addition, FAMACHA scores have potential to improve breeding value estimates in programs designed to genetically improve parasite resistance.

Key words: FAMACHA, gastrointestinal nematodes, Haemonchus contortus, sheep

\section{(C) 2017 American Society of Animal Science. All rights reserved.}

J. Anim. Sci. 2017.95:1118-1123 doi:10.2527/jas2016.1248

\footnotetext{
${ }^{1}$ Supported by Southern Region SARE (Project No. OS09-045), and USDA NIFA Organic Research and Education Initiative (Project No. 2010-51300-21641).

${ }^{2}$ The authors are grateful for the assistance of Jackie Cherry, Erin Smyth, Connie Cox, and Charles Lee at ARS, Booneville with data and sample collection and analyses. Thank you to the farmers and the volunteers and staff from Heifer Ranch International who posed researchable questions, collected samples and data, engaged in active discussion, and continue to inspire us.
} 


\section{INTRODUCTION}

The FAMACHA scoring system has been recommended as an on-farm strategy to monitor anemia and, by implication, parasite loads in sheep (Kaplan et al., 2004; Burke et al., 2007). Scores of 1 through 5 are assigned by comparing the color of animals' ocular mucous membranes to a color chart (Malan et al., 2001; Van Wyk and Bath, 2002). Under summer grazing conditions, the most likely cause of anemia in sheep flocks in the USA is parasitism by Haemonchus contortus, a blood-sucking abomasal nematode (Kaplan et al., 2004), and FAMACHA scoring has been recommended to allow identification and strategic deworming of animals with clinical infections with $H$. contortus. Strategic deworming of only symptomatic individuals can prevent or delay development of drug resistance in the worm population (van Wyk et al., 2002).

Because FAMACHA scores were developed based on blood packed cell volume (PCV; Malan et al., 2001; Vatta et al., 2001), a relatively strong relationship between these variables has been demonstrated in sheep and goats (Kaplan et al., 2004; Burke et al., 2007; Sotomaior et al., 2012). Riley and Van Wyk (2009) also reported heritable genetic variation in FAMACHA scores and postulated that selection for low scores could improve resistance and(or) resilience to infection with $H$. contortus. However, associations between FAMACHA scores and fecal egg counts (FEC) were often (Kaplan et al., 2004), though not always (Burke et al., 2007), less strong than those between FAMACHA scores and PCV. Fecal egg counts are generally considered to be the most effective measure of parasite resistance in live animals, and use of FAMACHA scores to improve resistance to $H$. contortus would require a substantial association between FAMACHA scores and FEC.

In this study, FAMACHA scores and FEC were recorded on growing lambs in 8 Katahdin sheep flocks and used to assess: 1) differences in lamb FEC, BW, and age associated with differences in FAMACHA scores at 2 measurement ages and 2) consistency of relationships between FAMACHA scores and FEC among flocks. Records came from a larger study (Notter et al., 2017) to characterize changes in FEC over time in peri-parturient ewes and their lambs.

\section{MATERIALS AND METHODS}

\section{Animals}

All animal procedures were approved by the Institutional Animal Care and Use Committee of the Agricultural Research Service (protocol \# USDA-ARS74-F-002). Lambs for this study came from 8 Katahdin sheep flocks including the USDA, ARS flock at the Dale Bumpers Small Farms Research Center in Booneville, AR, the Heifer International Ranch in Perryville, AR, and 6 private farms in Arkansas, Georgia, Ohio, Maine, and New York. Depending on the location, lambs were born in February through May, but within each location lambs were generally born within 4 to 8 wk windows. Flocks were located between 31.0 and 40.8 North latitude and between -74.0 and -93.9 West longitude. All flocks were located in areas considered to be vulnerable to parasitism with $H$. contortus, but for flocks located at higher latitudes the anticipated date of the onset of dangerous levels of parasitism was later, and mean lambing dates correspondingly tended to be later. Animals used for this study were derived from a larger study of changes in FEC over time in peri-parturient, primi- or multiparous Katahdin ewes and their lambs (Notter et al., 2017).

\section{Experimental Procedures}

The experimental protocol for this study called for lambs to be weighed, have FEC determined, and have FAMACHA scores assigned at approximately 90 and $120 \mathrm{~d}$ of age. However, some farms did not collect all data at both ages. The final data set thus included records of BW, FEC, and FAMACHA scores collected at 90 and $120 \mathrm{~d}$ in 7 and 6 flocks, respectively. Fecal samples were collected directly from the rectum, stored in a refrigerator at approximately $4^{\circ} \mathrm{C}$ for 1 to $7 \mathrm{~d}$, and then sent to Louisiana State University for determination of FEC using the McMaster procedure (Whitlock, 1948). At each sampling period, farmers were asked to collect a pooled sample of feces from at least 10 animals per farm for culture to determine the genera of the gastrointestinal nematodes (Peña et al., 2002). Between 1 and 4 pooled samples were collected per farm, but not in all years. For ARS collections, pooled fecal samples were collected at each sampling time. Farm managers were trained in assignment of FAMACHA scores by a certified trainer using a standard training protocol and materials according to the American Consortium for Small Ruminant Parasite Control (ACSRPC, 2006). Lambs with FAMACHA scores of 4 or 5 were dewormed, and lambs with a FAMACHA score of 3 were dewormed depending on recommendations found in the ACSRPC manual (ACSRPC, 2006). Weaning generally occurred between 90 and $120 \mathrm{~d}$ of age, but usually after recording of the 120 -d data.

\section{Statistical Methods}

The complete data set included records on 1,644 lambs from 7 flocks (A through G) sampled at approximately $90 \mathrm{~d}$ of age (range in age from 61 to 118 
d) and 1,295 lambs from 6 flocks (B, C, D, E, F, H) sampled at approximately $120 \mathrm{~d}$ of age (range in age from 90 to $152 \mathrm{~d}$ ). Samples were collected over $5 \mathrm{yr}$ (2009 through 2013) but all flocks did not contribute data in all years. For lambs sampled at approximately $90 \mathrm{~d}$ of age, data were contributed in 1 (2 flocks; A, E), 3 (2 flocks; B, G), 4 (1 flock; C), or 5 yr (2 flocks; D, F). Lambs produced within each flock were usually managed in a single group, but, in 3 cases, lambs born in the same flock and year were born at different times or otherwise managed differently and were therefore assigned to different management groups. Lambs born in these 8 flocks over $5 \mathrm{yr}$ were thus placed in 25 separate flock-year-management group classes. Body weights at $90 \mathrm{~d}$ were not recorded for lambs in 4 of these groups and were available for only 1,301 lambs.

For lambs sampled at approximately $120 \mathrm{~d}$ of age, data were reported in 1 (2 flocks; H), 3 (1 flock; B, D), 4 ( 1 flock; C), or 5 yr (2 flocks; D, F). In 3 cases, lambs born in the same flock and year were born at different times or managed differently and were assigned to different management groups. Body weights were not reported for lambs in 1 group and were available for 1,281 lambs. FEC and FAMACHA scores at both 90 and 120 $\mathrm{d}$ were available for 1,014 lambs from 4 flocks and 18 management groups. Any lamb that was dewormed at $90 \mathrm{~d}$ was not included in the $120 \mathrm{~d}$ analysis.

Fecal egg counts were transformed as LFEC = $\ln (\mathrm{FEC}+25)$ before analysis to improve normality. Resulting least-squares means (LSM) were presented on either the transformed scale or after back-transformation of LSM as (e $\left.e^{\mathrm{LSM}}-25\right)$. Standard errors of LSM were assumed to be approximately equal to $\mathrm{CV}$ of back-transformed means, and SE of back-transformed means were estimated by multiplying them by the SE of LSM.

All statistical models applied to these data included effects of flock and management group (nested within flock). Residual correlations among LFEC, FAMACHA scores, BW, and lamb ages at each measurement time were calculated after excluding lambs with missing BW and fitting this model. Repeatabilities of FEC, FAMACHA scores, and BW across measurement times was determined as residual correlations among these measurements after fitting the base model to observations for lambs that were evaluated at both measurement times. Differences in mean LFEC, BW, and lamb age among FAMACHA scores were also estimated at each measurement time by adding effects of FAMACHA score to the base model.

Consistency of differences in FEC among FAMACHA scores across flocks was evaluated using a model that included effects of flock, management group (nested within flock), FAMACHA score and the FAMACHA score $\times$ flock interaction. This model initially considered all 5 FAMACHA scores but was subsequently repeated after combining some adjacent FAMACHA scores to form 3 outcome groups that discriminated among lambs that were predicted to not require treatment (FAMACHA scores 1 and 2), to definitely require treatment (FAMACHA scores 4 and 5) or to be approaching or slightly anemic (FAMACHA score of 3). Lambs evaluated at $90 \mathrm{~d}$ in flock $\mathrm{E}$ had FAMACHA scores recorded in only $1 \mathrm{yr}$ and also has scores of only 1 or 2 . Records from this flock were therefore excluded from the analysis of consistency of FAMACHA effects at $90 \mathrm{~d}$.

\section{RESULTS}

The predominant genera of gastrointestinal nematodes cultured were $H$. contortus and Trichostrongylus spp. Other genera that were sometimes, but not always present were Cooperia spp., Oesophagostomum spp., and Teladorsagia spp. (less than $1 \%$ on one farm). Strongyloides spp. were present in lambs on 3 farms and ewes on 1 of those farms. Haemonchus contortus was present in all months of the study and on all farms.

Distributions of FAMACHA scores for each flock and measurement time are shown in Fig. 1. Variation among flocks in the incidence of lambs requiring treatment (i.e., with FAMACHA scores of 4 or 5) was substantial and, for flocks represented at both measurement times, ranged from 0 to $10.6 \%$ at $90 \mathrm{~d}$ and 2.5 to $35.2 \%$ at $120 \mathrm{~d}$. However, 1 flock that reported data in only $1 \mathrm{yr}$ and only at $90 \mathrm{~d}$ had a very high incidence of FAMACHA scores of 4 or $5(63.0 \%)$.

Residual correlations (r) among LFEC, FAMACHA scores, BW, and lamb age at each measurement time are shown in Table 1. At both 90 and $120 \mathrm{~d}$ of age, correlations of FAMACHA scores with LFEC and BW were highly significant $(P<0.001)$ but numerically modest $(0.25$ and -0.16 , respectively at $90 \mathrm{~d}$ and 0.31 and -0.16 , respectively at $120 \mathrm{~d}$ ). These results confirm that higher FAMACHA scores were associated with higher FEC and more likely to be observed in lighter lambs. A small negative association was observed between FAMACHA score and lamb age at measurement and was somewhat stronger at $120 \mathrm{~d}(P<0.001 ; r=-0.11)$ than at $90 \mathrm{~d}(P=0.05 ; r=-0.05)$. The residual SD in lamb age at each measurement time was approximately $6.2 \mathrm{~d}$, corresponding to a range in lamb ages within measurement times and lamb management groups of approximately $37 \mathrm{~d}$ (i.e., 6 residual SD). Within this range of ages, younger lambs were more likely to have elevated FAMACHA scores and anticipated to be more vulnerable to effects of parasitism.

Adding effects of FAMACHA score to the base model revealed large differences $(P<0.001)$ in mean FEC among FAMACHA scores at both 90 and $120 \mathrm{~d}$ (Fig. 2). 


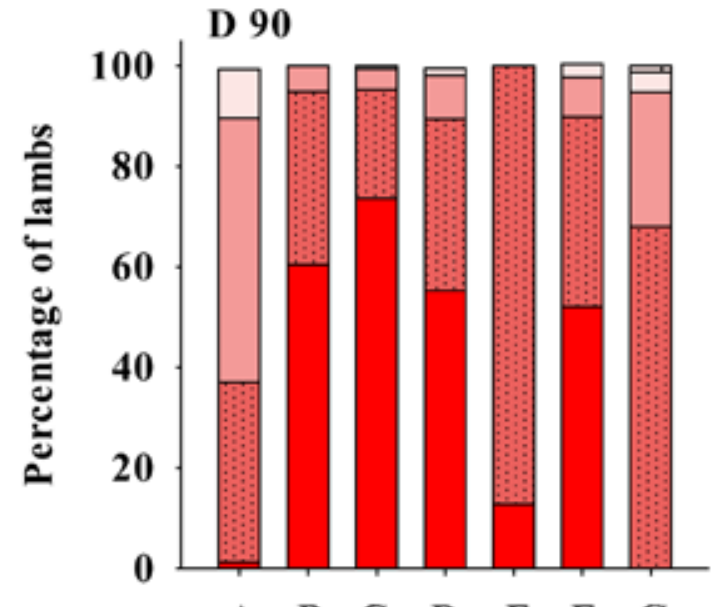

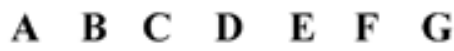

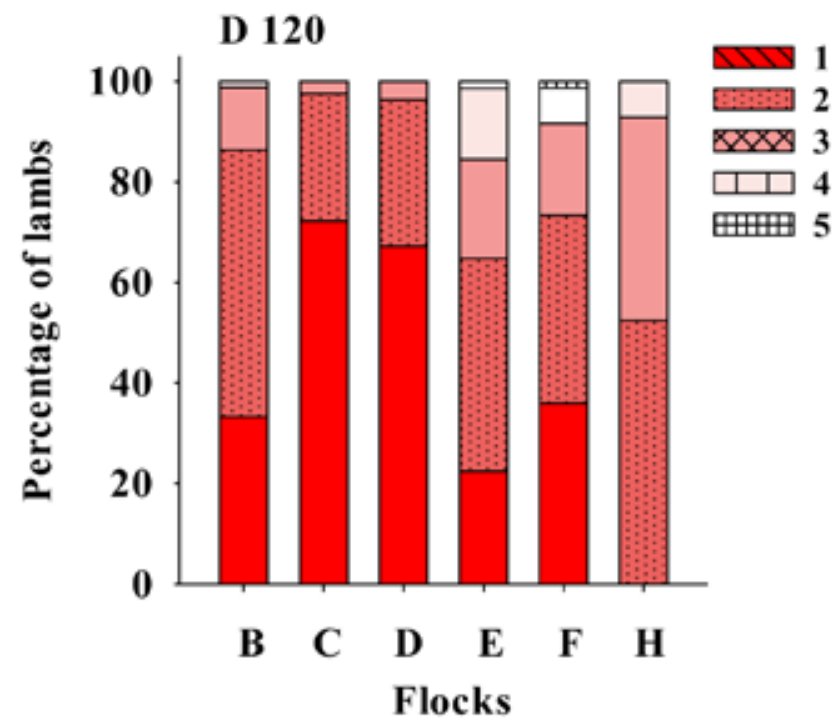

Figure 1. Distribution of FAMACHA scores 1 through 5, where $1=$ healthy or red fill; $5=$ extremely anemic or white fill, and reduced shades of red between 1 and 4) among flocks, represented by letters, and measurement times, 90 (top panel) and $120 \mathrm{~d}$ of age (bottom panel).

The relationship between FAMACHA score and LFEC was linear at both ages, although no difference in mean LFEC was observed for lambs with FAMACHA scores of 4 and 5 at $120 \mathrm{~d}$. Back-transformation of LFEC means to the original scale revealed an exponential increase in FEC with increasing FAMACHA scores (Fig. 2). Lambs with higher FAMACHA scores and associated higher mean FEC also weighed less $(P<0.001)$ and tended to be younger $(P=0.06$; Fig. 3$)$, confirming results of the correlation analysis. Relationships of FAMACHA scores with BW and lamb age were linear at both $90(P<0.001$ and $P=0.009$, respectively) and $120 \mathrm{~d}$ (both $P<0.001$ ).

Incorporation of flock $\times$ FAMACHA score interaction into the model revealed significant interaction effects on LFEC $(P=0.001)$ at both 90 and 120 d. Recoding the 5 FAMACHA scores into 3 outcome groups (Fig. 4) did not affect the significance of the flock $\times$ FAMACHA interaction at $90 \mathrm{~d}$ but improved consis-
Table 1. Correlations among FAMACHA scores (FAMACHA), log-transformed fecal egg counts (LFEC), BW, and age at measurement for Katahdin lambs at average ages of 90 (above the diagonal) and $120 \mathrm{~d}$ (below the diagonal)

\begin{tabular}{lllll}
\hline \hline & \multicolumn{4}{c}{ Variable } \\
\cline { 2 - 5 } Variable & FAMACHA & LFEC & BW & \multicolumn{1}{c}{ Age } \\
\hline FAMACHA & & $0.25^{* * *}$ & $-0.16^{* * *}$ & $-0.05^{*}$ \\
FEC & $0.31^{* * *}$ & & $-0.12^{* * *}$ & $-0.06^{*}$ \\
BW & $-0.16^{* * *}$ & -0.02 & & $0.28^{* * *}$ \\
Age & $-0.11^{* * *}$ & $-0.13^{* * *}$ & $0.25^{* * *}$ & \\
\hline$* P<0.05$. & & & \\
$* * * P<0.001$. & & &
\end{tabular}

tency of the observed relationship. At $120 \mathrm{~d}$, the flock $\times$ FAMACHA score interaction was not significant after recoding FAMACHA scores into Lambs outcome groups from 4 flocks $(n=1,014)$ had records at both measurement times. The repeatability of LFEC across measurement times (i.e., the residual correlation between LFEC at 90 and $120 \mathrm{~d})$ was $0.27(P<0.001)$; the repeatability of FAMACHA score was $0.21(P<0.001)$.

\section{DISCUSSION}

FAMACHA scores were developed using ranges of PCV (Malan et al., 2001; Vatta et al., 2001; Kaplan et al., 2004), such that there is an inverse relationship between these indices. Sheep are considered to be anemic when PCV falls below 19\%, and FAMACHA scores of 3 or
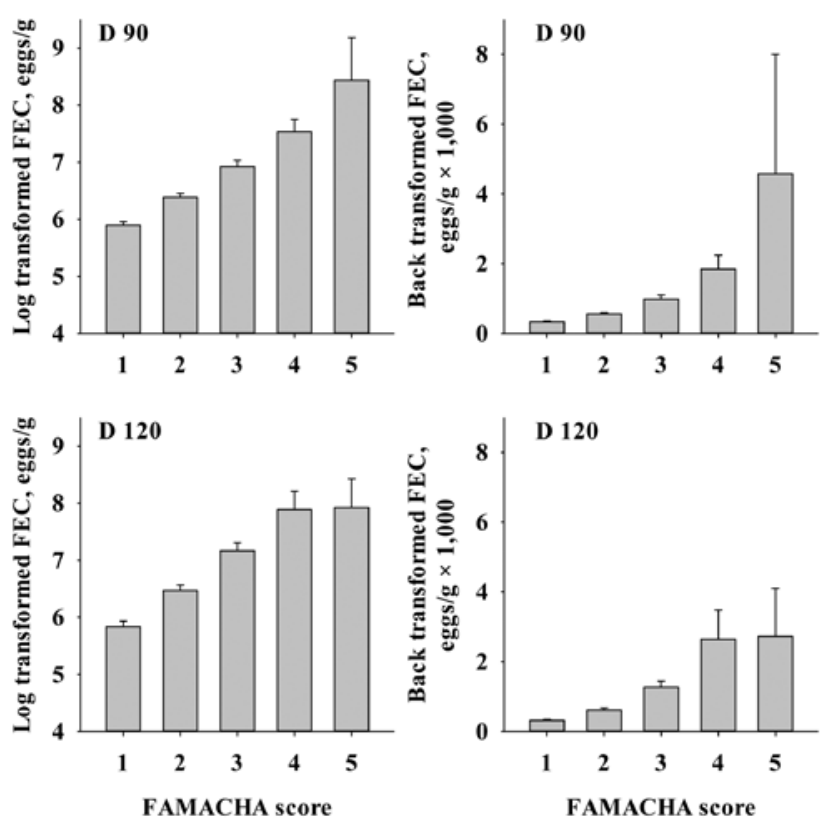

Figure 2. Least-squares means \pm SE for log-transformed fecal egg counts (FEC) by FAMACHA scores for lambs evaluated at approximately 90 and $120 \mathrm{~d}$ of age. Means are presented following logarithmic transformation of original values or after back-transformation of resulting leastsquares means to the original scale. 

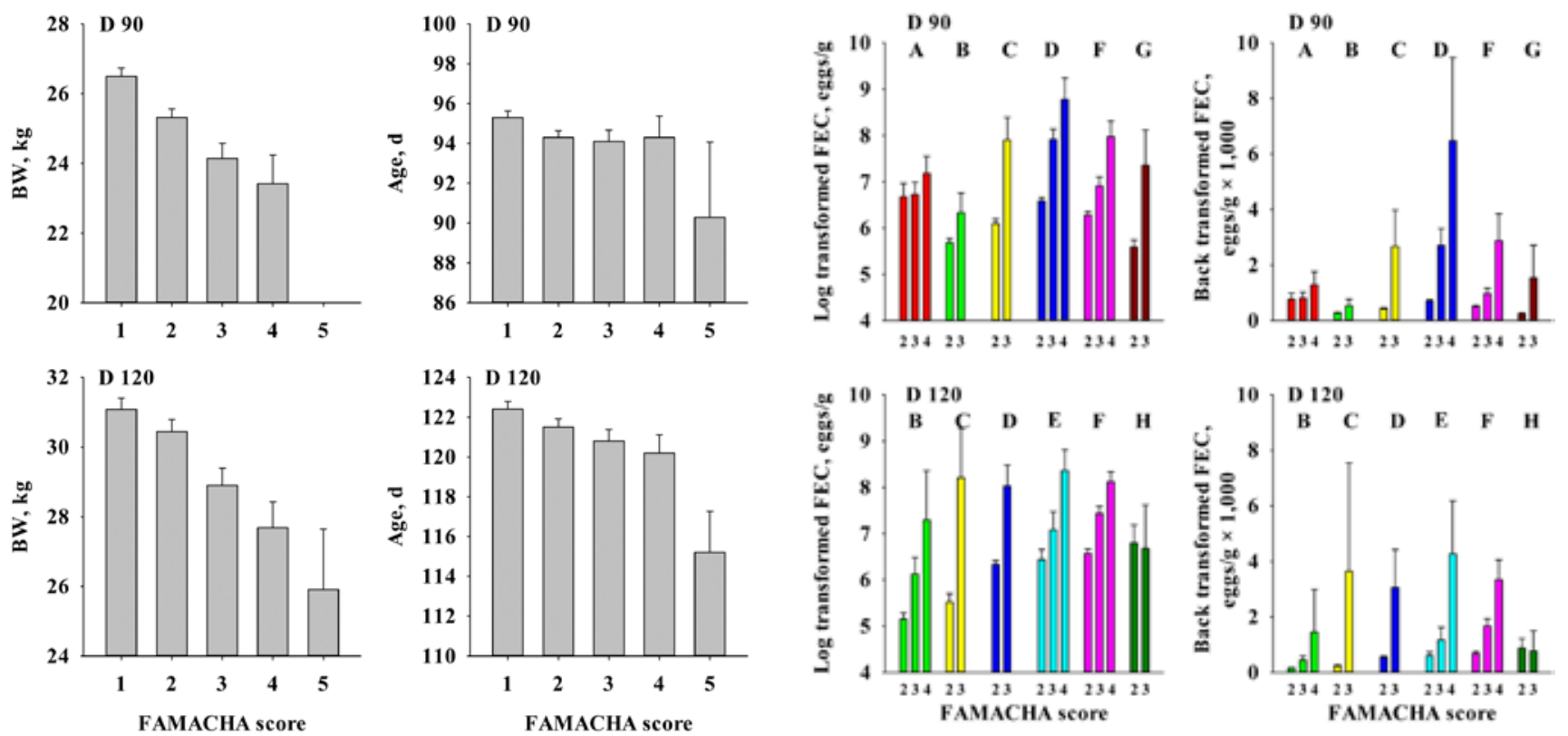

Figure 3. Least-squares means \pm SE for BW and lamb age by FAMACHA score for lambs evaluated at approximately 90 and $120 \mathrm{~d}$ of age.

greater are an indicator of anemia (Kaplan et al., 2004). However, a number of conditions can produce anemia, and the potential value of FAMACHA scores as an indicator of gastrointestinal nematode resistance relies on the assumption that observed anemia is primarily caused by blood loss arising from infection with $H$. contortus. Because $H$. contortus was not always the predominant nematode, as indicated by culture of worm eggs from some locations, FAMACHA score would not necessarily always reflect changes in FEC. However, when $H$. contortus is prevalent, FAMACHA scores reflect joint effect of resistance to gastrointestinal nematodes (i.e., the ability to avoid infection and expel larvae and adult nematodes from the gut) and resilience to infection (i.e., the ability to maintain normal levels of PCV despite the presence of adult nematodes in the gut). Selection for resistance, or for a combination of resistance and resilience, has advantages over selection for only resilience because animals that are resilient, but not resistant, continue to shed nematode eggs, contaminating pastures and increasing the opportunity for infection in nonresistant individuals and younger animals that have not yet developed resistance (Bishop, 2012). In particular, crossbred lambs produced by susceptible sire breeds face greater infection pressures if their dams are resilient to infection, but can be protected from infection by resistant dams. The value of FAMACHA scores for genetic improvement of gastrointestinal nematode resistance thus relies on a direct association between FAMACHA scores and FEC. This is best determined at a time of first exposure to $H$. contortus, typically between 90 and $120 \mathrm{~d}$ of age (Notter et al., 2017).

In the current study, this relationship was statistically significant, but numerically modest, with corre-
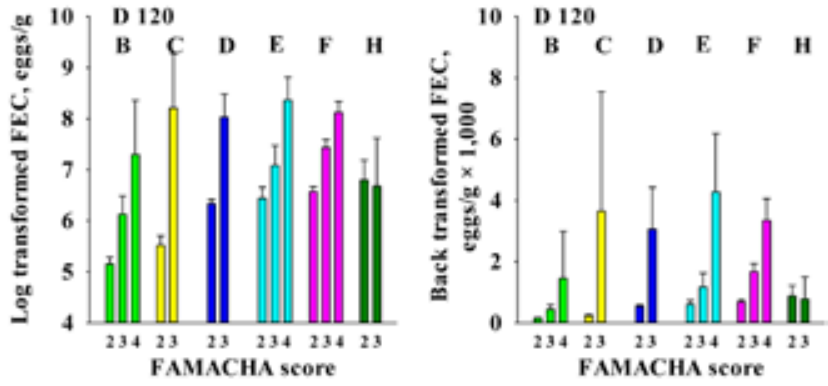

Figure 4. Association between least-squares means \pm SE for fecal egg counts (FEC) and FAMACHA outcome groups in different flocks for lambs evaluated at approximately 90 (flocks A- G) and $120 \mathrm{~d}$ (flocks B$\mathrm{H})$ of age. Means for FEC were derived following logarithmic transformation of original values and also shown following back-transformation of least-squares means to the original scale. FAMACHA outcome groups were derived by combining FAMACHA scores of 1 and 2 (indicated as 2 in $x$ axis labels) and of 4 and 5 (indicated as 4).

lations between log-transformed FEC and FAMACHA scores ranging from 0.25 at approximately $90 \mathrm{~d}$ to 0.31 at approximately $120 \mathrm{~d}$ of age. These associations were obtained with geometric means for FEC of approximately 1,000 eggs/g and mean FAMACHA scores of approximately 1.7 . These results are consistent with those of Burke et al. (2007) who reported a highly significant exponential increase in mean FEC with increasing FAMACHA scores in sheep and a correlation of 0.44 between FAMACHA score and FEC in lambs with an arithmetic mean FEC of approximately 945 eggs/g. However, in that study, PCV ranged from 8 to $47 \%$, but the correlation between FAMACHA scores and PCV was only 0.24 . Our results are also broadly consistent with those of Riley and Van Wyk (2009) who reported phenotypic correlations of 0.56 between FAMACHA scores and log-transformed FEC in 1,230 South African Merino lambs under conditions of peak gastrointestinal nematode challenge (geometric mean FEC of 5,710 eggs/g) and a mean FAMACHA score of 1.9.

A reasonable level of consistency among flocks in differences in mean FEC among FAMACHA scores was evident following log-transformation of FEC and grouping of FAMACHA scores into outcome groups (i.e., combining scores of 1 and 2 and scores of 4 and 5). Means for LFEC generally increased linearly across FAMACHA outcome groups, corresponding to exponential increases in back-transformed mean FEC. 
These results indicate that, with uniform training, consistency in the relationship between FAMACHA outcome groups and FEC can be achieved among flocks.

Fecal egg counts have been used as a predictor of breeding values for parasite resistance in industry programs in Australia and the U.S.A. (Notter, 2013; Brown and Fogarty, 2017), usually after application of logarithmic or cube-root transformation. Interest exists in using FAMACHA scores as an alternative or supplement to FEC measurements in prediction of breeding values for parasite resistance. Use of FAMACHA scores as an alternative to FEC would avoid the need for fecal collections and the expense of laboratory determination of FEC. FAMACHA scores were shown to be heritable in South African Merino sheep (Riley and Van Wyk, 2009), but the limited range in FAMACHA scores in most flocks would potentially also limit variation in resulting estimated breeding value. Use of FAMACHA scores to predict FEC would, however, be useful in flocks that practice selective deworming based on FAMACHA scores. In such flocks, selective deworming of highly parasitized lambs may invalidate later measurements of FEC in these lambs. However, lighter lambs from primi-parous ewes or ewes with lower milk production will be more susceptible to parasite infections due to poorer nutrition (Coop and Holmes, 1996) and may require salvage deworming. Results of the current study suggest that protocols to predict FEC for such lambs could potentially be developed. For example, at $120 \mathrm{~d}$, mean LFEC for lambs with FAMACHA scores of 3 and $\geq 4$ were 1.12 and 1.87 units higher than those for lambs with FAMACHA scores of $\leq 2$, corresponding to predicted increased in back-transformed mean FEC of 3.1- and 6.5-fold, respectively. These differences were consistent among flocks. At $90 \mathrm{~d}$, mean LFEC for lambs with FAMACHA scores of 3 and $\geq 4$ were 1.04 and 1.47 units higher than those for lambs with FAMACHA scores of $\leq 2$, corresponding to predicted increased in back-transformed mean FEC of 2.8- and 4.3-fold, respectively. However, effects of FAMACHA score on LFEC differed among flocks at $90 \mathrm{~d}$. Resulting FAMACHA-based estimates of FEC for previously dewormed lambs would, therefore, only be approximate, but would likely be superior to exclusion of these lambs from the FEC analysis. Therefore, we concluded that FAMACHA scores have potential to both facilitate selective deworming of highly parasitized individual lambs and improve breeding value estimates in programs designed to genetically improve parasite resistance.

\section{LITERATURE CITED}

ACSRPC. 2006. Smart drenching and FAMACHAC. Integrated training for sustainable control of gastrointestinal nematodes in small ruminants. http://media.wix.com/ugd/6ef604_68a22f c841a0486b9155ae1ed4121b0d.pdf. (Accessed 5 May 2016.)
Bishop, S. C. 2012. A consideration of resistance and tolerance for ruminant nematode infections. Front. Genet. 3:62-68. doi:10.3389/fgene. 2012.00168

Brown, D. J., and N. M. Fogarty. 2017. Genetic relationships between internal parasite resistance and production traits in Merino sheep. Anim. Prod. Sci. 57:2019-215. doi:10.1071/AN15469

Burke, J. M., R. M. Kaplan, J. E. Miller, T. H. Terrill, W. R. Getz, S. Mobini, E. Valencia, M. J. Williams, L. Williamson, and A. F. Vatta. 2007. Accuracy of the FAMACHAC system for on-farm use by sheep and goat producers in the southeastern U.S. Vet. Parasitol. 147:89-95. doi:10.1016/j.vetpar.2007.03.033

Coop, R. L., and P. H. Holmes. 1996. Nutrition and parasite interaction. Int. J. Parasitol. 26:951-962. doi:10.1016/S00207519(96)80070-1

Kaplan, R. M., J. M. Burke, T. H. Terrill, J. E. Miller, W. R. Getz, S. Mobini, E. Valencia, M. Williams, L. H. Williamson, M. Larsen, and A. F. Vatta. 2004. Validation of the FAMACHAC eye color chart for detecting clinical anemia on sheep and goat farms in the southern United States. Vet. Parasitol. 123:105-120. doi:10.1016/j.vetpar.2004.06.005

Malan, F. S., J. A. Van Wyk, and C. Wessels. 2001. Clinical evaluation of anaemia in sheep: Early trials. Onderstepoort J. Vet. Res. 68:165-174.

Notter, D. R. 2013. Selection for parasite resistance. Proc. XL Reunión de la Asociación Mexicana para la Producción Animal y la Seguridad Alimentaria y IX Seminario Internacional de Producción de Ovinos en el Trópico, Universidad Juárez Autónoma de Tabasco, Villahermosa, p. 3-12.

Notter, D. R., J. M. Burke, J. E. Miller, and J. L. M. Morgan. 2017. Factors affecting fecal egg counts in peri-parturient Katahdin ewes and their lambs. J. Anim. Sci. (in press).

Peña, M. T., J. E. Miller, M. E. Fontenot, A. Gillespie, and M. Larsen. 2002. Evaluation of Duddingtonia flagrans in reducing infective larvae of Haemonchus contortus in feces of sheep. Vet. Parasitol. 103:259-265. doi:10.1016/S0304-4017(01)00593-3

Riley, D. G., and J. A. Van Wyk. 2009. Genetic parameters for FAMACHA $\subset$ score and related traits for host resistance/ resilience and production at differing severities of worm challenge in a Merino flock in South Africa. Vet. Parasitol. 164:44-52. doi:10.1016/j.vetpar.2009.04.014

Sotomaior, C. S., R. Rosalinksi-Morais, A. R. Barbosa da Costa, D. Maia, A. L. G. Monteiro, and J. Van Wyk. 2012. Sensitivity and specificity of the FAMACHAC system in Suffolk sheep and crossbred Boer goats. Vet. Parasitol. 190:114-119. doi:10.1016/j.vetpar.2012.06.006

Van Wyk, J. A., and G. F. Bath. 2002. The FAMACHA ${ }^{\circledR}$ system for managing haemonchosis in sheep and goats by clinically identifying individual animals for treatment. Vet. Res. 33:509-529. doi:10.1051/vetres:2002036

van Wyk, J. A., G. C. Coles, and R. C. Krecek. 2002. Can we slow the development of anthelmintic resistance? An electronic debate. Trends Parasitol. 18:336-337. doi:10.1016/S14714922(02)02343-7

Vatta, A. F., B. A. Letty, M. J. van der Linde, E. F. van Wijk, J. W. Hansen, and R. C. Krecek. 2001. Testing for clinical anaemia caused by Haemonchus spp. In: goats farmed under resourcepoor conditions in South Africa using an eye colour chart developed for sheep. Vet. Parasitol. 99:1-14. doi:10.1016/ S0304-4017(01)00446-0

Whitlock, H. V. 1948. Some modifications of the McMaster helminth egg-counting technique apparatus. J. Counc. Sci. Ind. Res. 21:177-180. 
Reproduced with permission of copyright owner.

Further reproduction prohibited without permission. 